\title{
Influence of the Characteristics of Soil and Fly Ash on the Supercritical Carbon Dioxide Extraction of Dioxins
}

\author{
Ayato Kawashima, ${ }^{\dagger}$ Takashi MiYawaki, and Katsuhisa Honda \\ Environmental Science for Industry, Faculty of Agriculture, Ehime University, \\ 3-5-7 Tarumi, Matsuyama, Ehime 790-8566, Japan
}

\begin{abstract}
Several investigations on the extraction of dioxins from soil and fly ash with supercritical fluid have been reported; however, few of them describe the influence of components on the extraction. We extracted dioxins from eight samples with different values of organic carbon content and surface area with supercritical $\mathrm{CO}_{2}$ at a temperature of $463 \mathrm{~K}$, a pressure of $40 \mathrm{MPa}$, and using $10 \%$ toluene as an entrainer. We researched the influence of the characteristics of soil and fly ash on supercritical $\mathrm{CO}_{2}$ extraction of dioxins. The results revealed that the extraction efficiencies of PCDD/DFs and PCBs were high for all soil samples, while that of fly ash samples decreased with the increase in organic carbon content and surface area. The extraction efficiencies of dioxins from four standard samples, activated carbon, humic acid, alumina, and florisil, were also examined. The results revealed that the extraction efficiencies were strongly influenced by activated carbon like components present in the samples.
\end{abstract}

(Received July 4, 2006; Accepted August 1, 2006; Published November 10, 2006)

\section{Introduction}

In recent years, there has been an increased focus on the global environmental pollution caused by hazardous chemical compounds such as polychlorinated dibenzo-p-dioxins (PCDDs), polychlorinated dibenzofurans (PCDFs), and coplanar polychlorinated biphenyls (PCBs) that are lipophilic, persistent, bioaccumulative, and toxic. In order to study their dynamics in the environment, an analysis of dioxins over a wide range and continuous data acquisition are essential. In the quantitative method guidelines for dioxins in soil ${ }^{1}$ and fly ash, ${ }^{2}$ the Soxhlet extraction method with toluene as solvent has been employed. However, this extraction method requires prolonged operation and is cumbersome. There is also a concern regarding the working environment due to the extensive use of harmful organic solvents.

Supercritical $\mathrm{CO}_{2}$ extraction (SCE) has attracted much attention as an alternative to the Soxhlet extraction method due to its extraction selectivity, low critical point, non-flammability, non-toxicity, and non-corrosive characteristics. Many researchers have reported on the extraction of organic pollutants from soils and sediments by SCE; they reported that the extraction efficiency of SCE is equivalent to that of the Soxhlet extraction method. ${ }^{3-5}$ However, in the case of PCDD/DFs, which are particularly highly toxic organic pollutants, the extraction efficiency obtained by SCE is not sufficient as compared to that obtained by the Soxhlet extraction method. DeRoos $^{6}$ and Onuska ${ }^{7}$ pointed out that the inadequate extraction of PCDD/DFs from soils and sediments by SCE can be improved by the application of some other methods such as the addition of solvents to the supercritical $\mathrm{CO}_{2}$ as entrainer and chemical pretreatment before extraction..$^{8-10}$ During the

$\doteqdot$ To whom correspondence should be addressed.

E-mail: a-kawa@agr.ehime-u.ac.jp extraction of PCDD/DFs from fly ash, it was reported that the extraction efficiency of SCE with the addition of solvents or chemical pretreatment before the extraction was equivalent to that of the Soxhlet extraction method. ${ }^{10-15}$ However, some reports suggest that the extraction efficiency obtained in the case of fly ash sample was not sufficient and that the material contained a significant amount of carbon components. ${ }^{16-18}$ As mentioned above, there have been several reports on the extraction of dioxins from soil and fly ash with supercritical fluid. However, the extraction efficiencies vary from one report to another and only a few of them describe the influence of components present in the sample on the extraction.

In this study, we intended to elucidate the influence of the characteristics of soil and fly ash on the SCE of dioxins. We extracted dioxins by SCE and Soxhlet extraction from four soil samples with different values of organic carbon content and surface area. The obtained data were compared with our previously reported data of four fly ash samples, ${ }^{18}$ and the influence of components on the extraction was examined. Furthermore, XRD analysis was performed in an attempt to investigate the structure of the contents in the fly ash samples. We also examined the extraction efficiencies of dioxins by SCE from four standard samples, activated carbon, humic acid, alumina, and florisil, as the basic components in the soil and fly ash samples. The influence of the components present in the samples was also discussed.

\section{Experimental}

Reagents and sample preparation

Analytical-grade solvents such as hexane, dichloromethane, and toluene were purchased from Wako Pure Chemical Industries (Osaka, Japan). PCDD/DFs and PCBs standards were purchased from Wellington Laboratories (Canada). Other chemicals such as acids, bases, and salts were obtained from 
Table 1 Characteristics of the examined soil and fly ash samples

\begin{tabular}{clcc}
\hline Sample & \multicolumn{1}{c}{ Location } & $\begin{array}{c}\text { Dioxin content/ } \\
\text { pg-TEQ g }^{-1}\end{array}$ & $\begin{array}{c}\mathrm{H}_{2} \mathrm{O} \\
\text { content, \% }\end{array}$ \\
\hline Soil & & & \\
A & Old factory site & 150 & 1.2 \\
B & Forest & 160 & 11 \\
C & Paddy & 48 & 8.2 \\
D & Old factory site & 42 & 6.5 \\
Fly ash & & 15000 & - \\
E & Stoker-fired furnace & 4200 & - \\
F & Gasification melting furnace & 1500 & - \\
G & Gasification melting furnace & 5800 & - \\
H & Stoker-fired furnace & & \\
\hline
\end{tabular}

Wako Pure Chemical Industries (Japan) and Nacalai Tesque (Tokyo, Japan).

The characteristics of the examined soil and fly ash samples are summarized in Table 1. Four soil samples (A-D) were obtained from different sampling points. The samples were broken into pieces and dried in air at room temperature for two weeks. The dried samples were passed through a $2 \mathrm{~mm}$ sieve and maintained in sealed brown bottles at room temperature.

Four fly ash samples $(\mathrm{E}-\mathrm{H})$ were obtained from different waste incinerators in Japan and maintained in sealed brown bottles at room temperature.

The fly ash samples were pretreated with $\mathrm{HCl}$ (in order to remove the alkaline salts) before extraction in accordance with the quantitative method guidelines for dioxins ${ }^{2}$ as follows: A fly ash sample (1 $\mathrm{g}$ for SCE and $5 \mathrm{~g}$ for Soxhlet extraction) was mixed with $100 \mathrm{ml}$ of $2 \mathrm{M} \mathrm{HCl}$ and the mixture was allowed to stand for $1 \mathrm{~h}$. This mixture was filtered, washed with water, and dried on a hot plate at $333 \mathrm{~K}$ for $12 \mathrm{~h}$. The dried sample was used in the extraction experiments. The weight reductions between the pretreated fly ash samples and the original ones were $10,9.5,15$, and $9.3 \%$ for fly ash samples $\mathrm{E}, \mathrm{F}, \mathrm{G}$, and $\mathrm{H}$, respectively.

The surface area was measured with a surface area measuring instrument, SURFACE AREA HPP.SA-100 (SHIBATA, Japan).

The organic carbon contents of each soil and fly ash sample were analyzed by an elemental analyzer, CHN coder MT-5 (YANACO, Japan). Each soil sample was washed with $\mathrm{HCl}$ and dried before analysis in order to remove the inorganic carbon.

X-ray powder diffraction (XRD) analysis was performed with a MiniFlex X-ray diffractometer equipped with monochromatic $\mathrm{CuK} \alpha$ radiation (Rigaku, Japan).

Dioxins-containing standard samples were prepared as follows: activated carbon, humic acid, alumina, and florisil were used as standard materials. All standard materials were commercially available (Kanto Chemical Co. Inc., Tokyo, Japan). The surface areas of the standard materials were 1070 , 4,140 , and $140 \mathrm{~m}^{2} / \mathrm{g}$ for activated carbon, humic acid, alumina, and florisil, respectively. All the materials were washed with toluene in a Soxhlet for $16 \mathrm{~h}$ and were dried at $373 \mathrm{~K}$ in a vacuum. Then, $80 \mathrm{ml}$ of hexane and $1.2 \mathrm{ml}$ of dioxins standard hexane solution was added to $24 \mathrm{~g}$ of each standard material and mixed well. Each mixture was evaporated and dried. The concentration of each congener in dioxins-containing standard samples was $500 \mathrm{pg}$ of tetra- to penta-CDD/DFs, $1000 \mathrm{pg}$ of hexa- to hepta-CDD/DFs, $2500 \mathrm{pg}$ of octa-CDD/DFs, and 500 $\mathrm{pg}$ of each congener of PCBs in $1 \mathrm{~g}$ of the standard material.

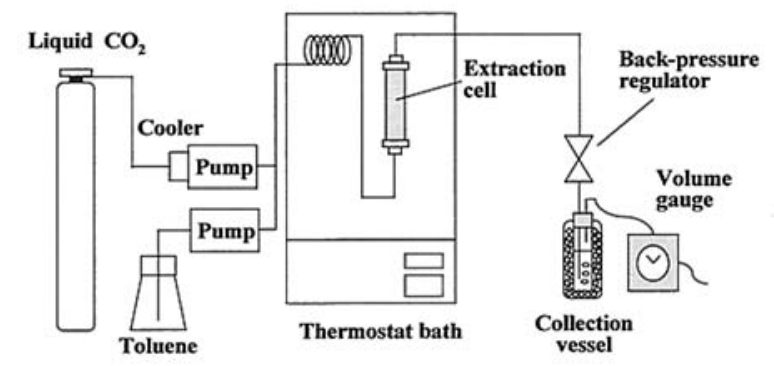

Fig. 1 Schematic diagram of the experimental apparatus for supercritical fluid extraction.

Supercritical extraction, Soxhlet extraction, and analysis

A schematic diagram of the SCE apparatus is shown in Fig. 1. The sample was inserted in the extraction cell $(150 \mathrm{~mm} \times 1 / 2$ inch OD, SUS316). The extraction cell was sealed and the $\mathrm{CO}_{2}$ delivery pump PU-2080 (JASCO International, Japan) was attached to it along with a back pressure regulator SCF-Bpg (JASCO International, Japan) and a restrictor tube (1/16 SUS316). The extract flowing from the restrictor tube was trapped in a collection vessel with $100 \mathrm{ml}$ hexane. The volume of $\mathrm{CO}_{2}$ was measured using a dry gas test meter DC-1 (Shinagawa, Japan). The weights of the samples used in SCE were 3,1 , and $2 \mathrm{~g}$ for the soil sample, fly ash sample (original weight before $\mathrm{HCl}$ treatment), and standard sample, respectively. The optimal extraction condition, a temperature of $463 \mathrm{~K}$, a pressure of $40 \mathrm{MPa}$, and $10 \%$ toluene as entrainer, of SCE was determined on the basis of our previous research. ${ }^{9}$ The extraction cell with the inserted sample was heated in a thermostat bath to $463 \mathrm{~K}$ and then $\mathrm{CO}_{2}$ was pumped into the cell. At $40 \mathrm{MPa}$, supercritical $\mathrm{CO}_{2}$ and toluene were introduced at 2 and $0.2 \mathrm{ml} / \mathrm{min}$, respectively. The total $\mathrm{CO}_{2}$ volume was set to $40 \mathrm{~L}$ at standard temperature and pressure. The extracted sample collected with hexane in the recovery flask was analyzed as described below.

Soxhlet extraction and analysis were performed in accordance with the quantitative method guidelines for dioxins. ${ }^{1,2}$ The weights of the samples used in Soxhlet extraction were 10, 5, and $2 \mathrm{~g}$ for the soil sample, fly ash sample (original weight before $\mathrm{HCl}$ treatment), and standard sample, respectively. The Soxhlet extraction was performed for more than $16 \mathrm{~h}$.

The extracted samples were analyzed as follows: ${ }^{13} \mathrm{C}$-labeled PCDD/DFs and PCBs were added to the extracted samples as internal standards and the materials were concentrated. The samples were applied to a multilayer silica gel column and concentrated. The eluent was applied on a reversible activated carbon-dispersed silica gel column. The resultant eluents were spiked with a ${ }^{13} \mathrm{C}$-labeled injection spike and subjected to chemical analyses of PCDD/DFs and PCBs. The identification and quantification of PCDD/DFs and PCBs were performed by high-resolution gas chromatography coupled with a highresolution mass spectrometric detector (HRGC/HRMSD) (Agilent 6890/JEOL JMS-700D, Agilent 6890/JEOL JMS-800) at a resolution of $>10000$. An SP2331 capillary column (film thickness: $0.20 \mu \mathrm{m}, 0.25 \mathrm{~mm}$ i.d., length: $60 \mathrm{~m}$, Supelco, USA) was used for the quantification of tetra- to hexa-CDD/DFs, and an RH-12ms capillary column $(0.25 \mathrm{~mm}$ i.d., length: $60 \mathrm{~m}$, Inventx, USA) was used for the quantification of 1,2,3,7,8,9HxCDF, hepta- to octa-CDD/DFs, and coplanar PCBs. $\mathrm{PCDD} / \mathrm{DFs}$ and coplanar PCBs were monitored in the selective ion monitoring mode at two intensive ions of the molecular ion cluster and quantified using the corresponding ${ }^{13} \mathrm{C}$-labeled 


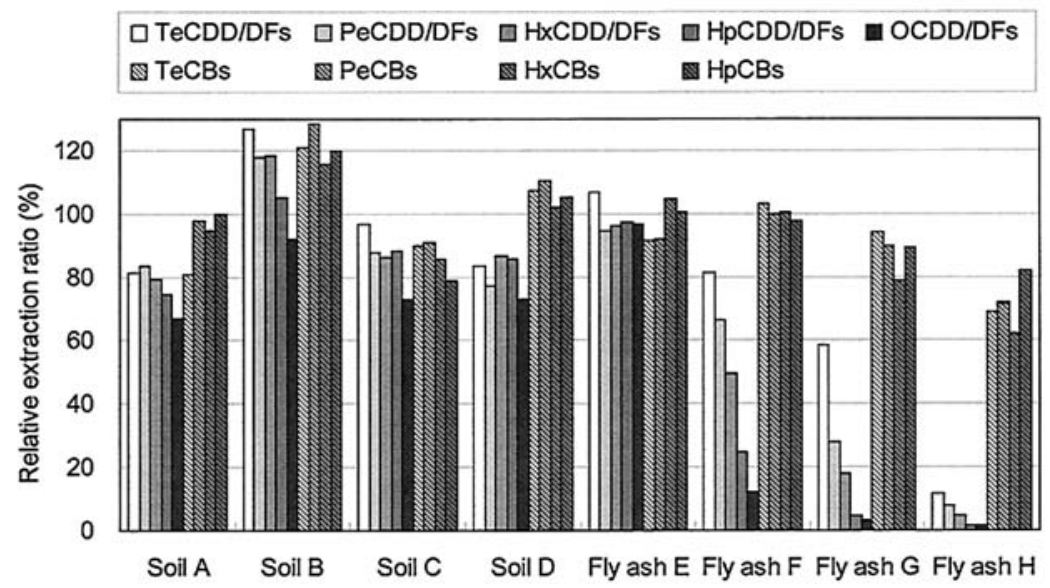

Fig. 2 Relative extraction ratios (\%) of PCDD/DFs and PCBs with supercritical fluid extraction for soils and fly ashes. ${ }^{18}$ The relative extraction ratios are relative ratios, i.e., the extracted concentration of SCE/the extracted concentration of Soxhlet $\times 100$. The value indicates the mean value of the relative extraction ratio of each isomer of $\mathrm{PCDD} / \mathrm{DFs}$ and $\mathrm{PCBs}$.

Table 2 Surface areas and organic carbon contents of the examined soils and fly ashes ( $\mathrm{m}^{2} /$ original-g)

\begin{tabular}{|c|c|c|c|c|c|c|c|c|}
\hline & \multicolumn{4}{|c|}{ Soil } & \multicolumn{4}{|c|}{ Fly ash } \\
\hline & A & B & $\mathrm{C}$ & $\mathrm{D}$ & E & F & $\mathrm{G}$ & $\mathrm{H}$ \\
\hline Surfa & 6.1 & 12 & 20 & 28 & $3.1^{\mathrm{a}}$ & $7.9^{\mathrm{a}}$ & $23^{\mathrm{a}}$ & $34^{\mathrm{a}}$ \\
\hline Organic carbon & 36 & 100 & 18 & 40 & $9.2^{\mathrm{a}}$ & $4.5^{\mathrm{a}}$ & $21^{\mathrm{a}}$ & $42^{\mathrm{a}}$ \\
\hline
\end{tabular}

a. For the fly ash samples, these values are measured after the treatment with $\mathrm{HCl}^{18}$

congeners. The detection limit of the individual congeners was $0.3-10 \mathrm{pg} / \mathrm{g}$ on a dry weight basis. The validation of the method resulted in a precision within $20 \%$.

\section{Results and Discussion}

The surface areas and organic carbon contents of the examined soils and fly ashes are listed in Table 2 . The values of surface area are in the range of 3.1 to $34 \mathrm{~m}^{2} / \mathrm{g}$, and the organic carbon contents are in the range of 4.5 to $100 \mathrm{mg} / \mathrm{g}$. Figure 2 shows the relative extraction ratios (\%) of the PCDD/DFs and PCBs with SCE for the eight samples with different surface areas and organic carbon contents. For PCDDs and PCDFs, the relative extraction ratio is collectively shown because the extraction behavior of each isomer with the same chlorine number congener is similar. These relative extraction ratios were indicated as the relative ratios of SCE to Soxhlet extractions. The relative extraction ratios of $\mathrm{PCDD} / \mathrm{DFs}$ and $\mathrm{PCB}$ s from soil samples A, B, C, and D were in the range of 80 to $120 \%$ and their extraction efficiencies were approximately the same as those obtained by the Soxhlet extraction method. In contrast, the relative extraction ratios for fly ash samples varied widely among the PCDD/DFs isomers except for fly ash sample E. The relative extraction ratios for PCDD/DFs were essentially low and decreased with the increase in the number of $\mathrm{Cl}$ atoms.

The relative extraction ratios, surface areas, and organic carbon contents are plotted in Fig. 3 in order to reveal the correlation between characteristics of the samples and their extraction ratios. The relative extraction ratios of SCE for soil

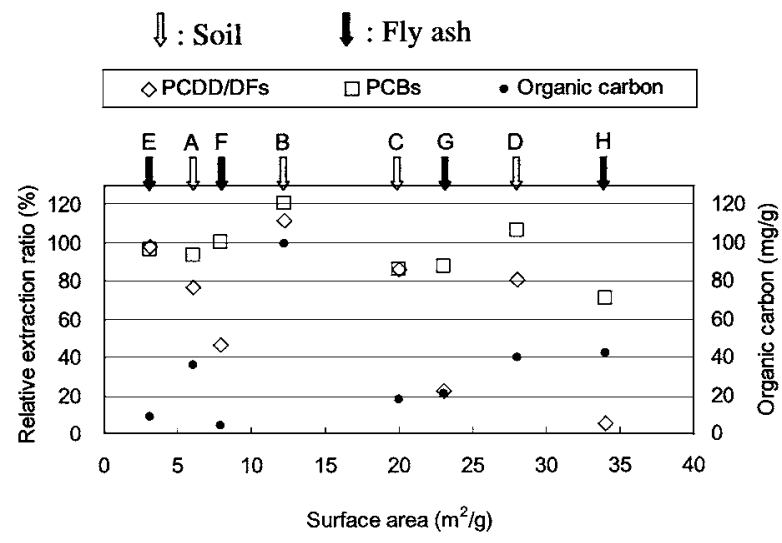

Fig. 3 Correlation between the relative extraction ratios and sample characteristics of soils and fly ashes. ${ }^{18}$ The relative extraction ratios were average values of each congener of PCDD/DFs and PCBs. The amount of organic carbon was plotted on the vertical right axis and the surface area was plotted on the horizontal axis.

samples were equivalent to those of the Soxhlet extraction regardless of their surface areas and organic carbon contents. However, the relative extraction ratios of PCDD/DFs and PCBs, especially of PCDD/DFs from the fly ash samples, clearly decreased with the increase in surface area. The obtained ratios of PCDD/DFs for fly ash samples $\mathrm{G}$ and $\mathrm{H}$ were 23 and $5 \%$, respectively.

In addition, the organic carbon contents of fly ash $\mathrm{G}$ and fly ash $\mathrm{H}$ were higher as compared to those of the other fly ash samples. It is believed that the presence of organic carbon in fly ash significantly influences its extraction ratio. In the soil sample, even if the amount of organic carbon content exceeds $100 \mathrm{mg} / \mathrm{g}$, its extraction efficiency is equivalent to that of the Soxhlet extraction method. However, a relatively low extraction ratio was observed in the case of fly ash containing $20 \mathrm{mg} / \mathrm{g}$ of organic carbon. This is probably due to the different forms of organic carbon which exists in soil and fly ash.

Generally, in soil, organic carbon exists as a humic acid like chemical form. However, in fly ash, it exists as activated carbon or as graphite like chemical form due to its thermal 


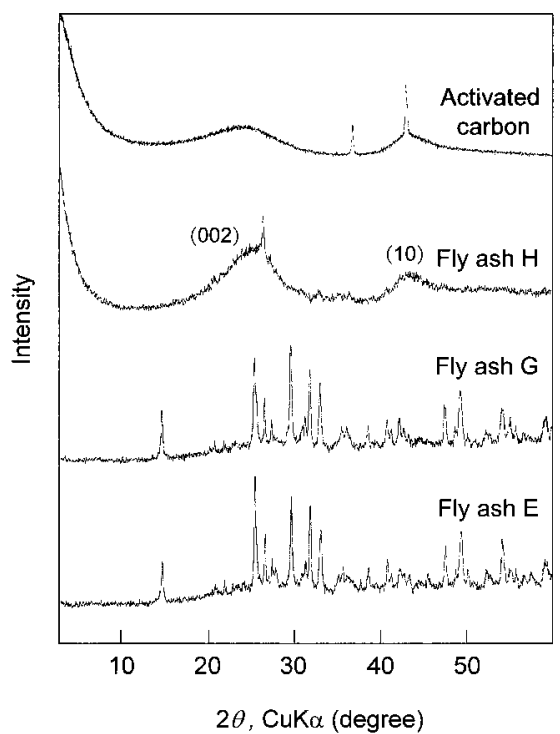

Fig. 4 Powder XRD patterns for fly ash samples E, G, H, and activated carbon as standard.

history. ${ }^{19,20}$ In addition, it is possible that, in the case of especially high organic carbon content samples, the activated carbon is blown on incineration in order to remove pollutants. For example, the surface area of fly ash $\mathrm{H}$ was estimated to be $34 \mathrm{~m}^{2} / \mathrm{g}$; however, the weight of the original sample reduced from $1 \mathrm{~g}$ to $93 \mathrm{mg}$ after the $\mathrm{HCl}$ treatment. Therefore, the surface area of the pretreated fly ash $\mathrm{H}$ was $34 / 0.093=366$ $\mathrm{m}^{2} / \mathrm{g}$, which was quite large. The organic carbon content of the pretreated fly ash $\mathrm{H}$ was estimated to be $42 / 93=0.45(45 \%)$ and it accounted for approximately half of its weight.

$\mathrm{XRD}$ analysis which is an effective method to analyze the crystal structure of organic carbon, was performed in an attempt to examine the structure of the contents in the fly ash samples. Figure 4 shows the powder XRD patterns for fly ash samples E, $\mathrm{G}$, and $\mathrm{H}$. The pattern for a commercially available activated carbon is also shown in the figure for comparison. Fly ash $\mathrm{H}$ exhibits two broad peaks that can be assigned to the (002) and (10) diffraction lines confirming the randomly oriented multilayer carbon, as shown in the pattern of the activated carbon. This result clearly suggests that fly ash $\mathrm{H}$ contains activated carbon like organic carbon. Fly ash samples E, F (not shown), and $G$ exhibit no clear peaks corresponding to the activated carbon. However, some sharp peaks corresponding to inorganic materials were observed. Also, fly ash G appears to contain an activated carbon like organic carbon because the extraction ratios are low, the surface area is $151 \mathrm{~m}^{2}$, and the organic carbon content is $14 \%$. Since XRD analysis is not sensitive if the amount of phase is too low and/or for a low degree of crystallization of carbon sample, no clear pattern of carbon is observed in the case of fly ash sample G.

These results indicated that the fly ash sample with a large surface area and a high organic carbon content should contain activated carbon like organic carbon and therefore the observed extraction efficiency of SCE was not sufficient. It is believed that extraction efficiency is significantly influenced by the form of organic carbon component present in a sample.

To elucidate the influence of components in extracted samples, the extraction of PCDD/DFs and PCBs from standard samples, humic acid as organic carbon in soil, activated carbon as organic carbon in fly ash, and alumina and florisil as other

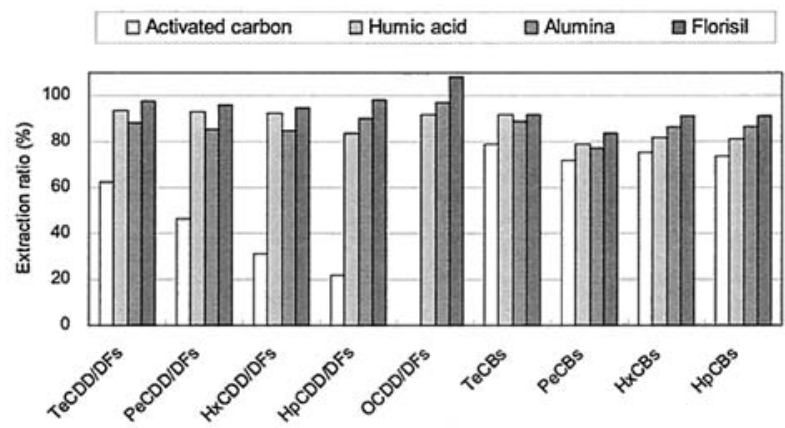

Fig. 5 Extraction ratios of PCDD/DFs and PCBs by Soxhlet extraction method from standard samples. These extraction ratios are the relative ratios of the extracted to the added concentration of the PCDD/DFs and PCBs of each standard sample. The value indicates the mean value of the extraction ratio of each isomer of PCDD/DFs and PCBs.

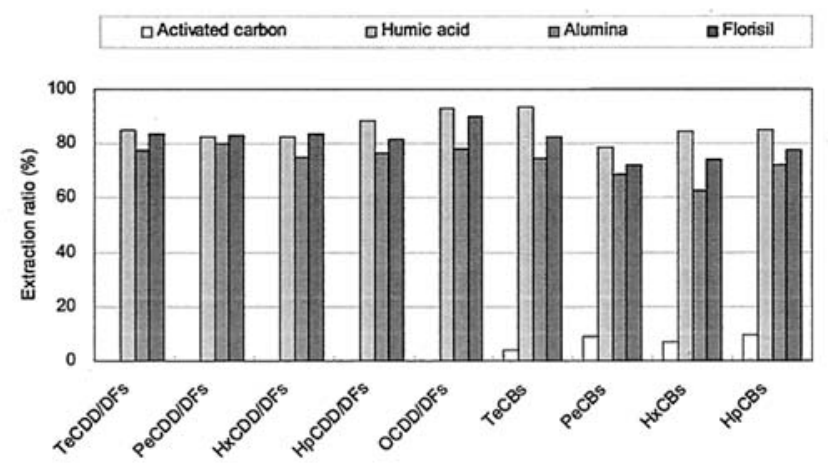

Fig. 6 Extraction ratios of PCDD/DFs and PCBs by supercritical fluid extraction from standard samples. These extraction ratios are the relative ratios of the extracted to the added concentration of the PCDD/DFs and PCBs of each standard sample. The value indicates the mean value of the extraction ratio of each isomer of PCDD/DFs and PCBs.

components, by Soxhlet extraction and SCE were examined. The extraction ratios of Soxhlet extraction are shown in Fig. 5. The extraction ratios of humic acid, alumina, and florisil were more than $80 \%$ and resulted in high yields for PCDD/DFs and PCBs. However, in the case of activated carbon, the ratios for PCBs were about $70 \%$ and the ratios for PCDD/DFs decreased with the increase in the number of $\mathrm{Cl}$ atoms. Especially, for OCDD/DFs the extraction ratio was almost $0 \%$. It indicates that it is difficult to extract PCDD/DFs from the activated carbon, especially the highly chlorinated PCDD/DFs, even by the Soxhlet extraction method.

Figure 6 shows the extraction ratios of PCDD/DFs and PCBs by SCE from standard samples. The extraction ratios of PCDD/DFs and PCBs from humic acid, alumina, and florisil were in the range of 65 to $95 \%$, and extraction efficiencies similar to those of the Soxhlet extraction method were observed. However, in the case of activated carbon, the extraction of PCDD/DFs was difficult to achieve and the extraction efficiency was very low, even for PCBs. Such results indicate that the extraction of PCDD/DFs and PCBs from activated carbon by using the Soxhlet extraction method and SCE was difficult because of its high absorbability with respect to $\mathrm{PCDD} / \mathrm{DF}$ s and PCBs. 
The results of these experiments revealed that the use of SCE for extraction is sufficient for soil samples with organic carbon mainly in the form of humic acid, and for fly ash samples with their small surface area and low organic carbon content. However, in the case of fly ash samples with a large surface area and high organic carbon content, there is a high possibility that they might contain an activated carbon like structure due to the formation of activated carbon by thermal history and/or blowing into the incinerator. In such cases, it was observed that it is difficult to achieve the extraction of PCDD/DFs by not only the SCE but also by the Soxhlet extraction method.

$\mathrm{PCDD} / \mathrm{DFs}$ and PCBs consist of an aromatic ring and are hydrophobic. In particular, the planar and highly chlorinated PCDD/DFs can interact strongly with planar aromatic surfaces such as activated carbon due to their intermolecular interaction. Therefore, in the case of samples containing such activated carbon like structure, it would be required that they are extracted under a higher solvation condition and at a high temperature in order to weaken their interaction and achieve high extraction efficiency.

\section{Conclusion}

In this study, we have described the influence of the characteristics of soil and fly ash on the SCE of dioxins. These experiments showed that the extraction efficiencies of PCDD/DFs and PCBs were relatively high for all soil samples. However, for fly ash samples, their extraction efficiencies decreased with the increase in organic carbon content and surface area due to the adsorbability of activated carbon like organic carbon in fly ash.

As compared to the Soxhlet extraction method, the SCE method is non-organic-solvent, rapid, and allows high selectivity and safe extraction. However, it became clear that the characteristics of the contents present in the sample, especially in organic carbon, significantly influence the extraction efficiency. Therefore, it is essential to select the extraction method and condition based on the feature of the sample.

\section{References}

1. "Manual for the Survey and Measurement of Dioxins in Soil", 2000, Japan, Soil and Agricultural Chemicals Division, Water Quality Bureau, Environment Agency.

2. JIS (Japan Industrial Standard), K 0311, 1999.

3. S. B. Hawthorne and D. J. Miller, Anal. Chem., 1994, 66, 4005.

4. S. Bøwadt, L. Mazeas, D. J. Miller, and S. B. Hawthorne, J. Chromatogr., A, 1997, 785, 205.

5. Y. Arahori and K. Yasumura, Kankyo Kagaku, 2002, 12, 789.

6. F. L. DeRoos and M. K. Bicking, Chemosphere, 1990, 20, 1355.

7. F. I. Onuska and K. A. Terry, J. High Resol. Chromatogr., 1991, 14, 829 .

8. T. Miyawaki, A. Kawashima, and K. Honda, Bunseki Kagaku, 2005, 54, 43.

9. T. Miyawaki, A. Kawashima, and K. Honda, Bunseki Kagaku, 2005, 54, 707.

10. C. Friedrich and W. Kleibohmer, J. Chromatogr., A, 1997, $777,289$.

11. I. Onuska, K. A. Terry, and R. J. Wilkinson, J. High Resol. Chromatogr., 1993, 16, 407.

12. J. W. Hills, H. H. Hill, Jr., D. R. Hansen, and S. G. Metcalf, J. Chromatogr., A, 1994, 679, 319.

13. S. Kawajiri, M. Goto, and T. Hirose, Organohalogen Compounds, 2000, 45, 101.

14. N. Alexandrou and J. Pawliszyn, Anal. Chem., 1989, 61, 2770.

15. J. J. Langenfeld, S. B. Hawthorne, D. J. Miller, and J. Pawliszyn, Anal. Chem., 1995, 67, 1727.

16. I. Windal, G. Eppe, A. C. Gridelet, and E. D. Pauw, J. Chromatogr., A, 1998, 819, 187.

17. I. Windal, D. J. Miller, E. De Pauw, and S. B. Hawthorne, Anal. Chem., 2000, 72, 3916.

18. A. Kawashima, S. Kato, T. Miyawaki, and K. Honda, Kankyo Kagaku, 2005, 15, 397.

19. S. Nagano, H. Tamon, T. Adzumi, K. Nakagawa, and T. Suzuki, Carbon, 2000, 38, 915.

20. Z. Sarbak and M. Kramer-Wachowiak, Powder Technol., 2002, 123, 53. 